\title{
The Effectivity of 3D Interactive Multimedia to Increase the Students' Visuospatial Abilities in Molecular
}

\author{
Abdul Aziz Tamami ${ }^{1}$, Kusumawati Dwiningsih ${ }^{2}$ iD \\ Faculty of Mathematics and Natural Sciences, Universitas Negeri Surabaya, Indonesia
}

*Corresponding author: kusumawatiningsih@unesa.ac.id

\begin{abstract}
This research and development aims to develop interactive 3D multimedia that appropriate to increase students' visuospatial abilities at molecular shapes geometry studies. This research and development use the modified research and development 4D Thiagarajan design model that limiting until the development testing step. The descriptive qualitative analysis is used to assess the data result. The multimedia effectiveness is stated based on the increasing right-answered percentage and N-Gain score interpretation. The result shows that it has an increasing right-answered percentage $>50 \%$ in each test indicator and signification rate at range 0,5174 - 1,0000 in the medium until high level. The achievement of two kind effectiveness' criteria can be stated that interactive 3D multimedia is appropriate as the effective learning media to increase student's visuospatial abilities. Visual model in 2D and 3D utilization can aid the students' representation skill, so that it can be applied to the other relevant matter.
\end{abstract}

Keywords: Interactive Multimedia, Molecular Shapes Geometry, Effectiveness, Visuospatial Abilities.

History:
Received $\quad$ : 25 June 2020
Revised $\quad$ : 27 July 2020
Accepted $\quad$ : 23 Auggust 2020
Published $: 7$ October 2020

Published : 7 October 2020

\section{Introduction}

Natural science is the matter that has an important role caused the function and implementation closely related to our daily life. This role causes this matter are important to be understood in school. Natural science is consisting of branches that explain nature characteristics from various perspectives. Chemistry is also known as the center of nature science besides other various natural science branches (Ghibaudi, 2019). Chemistry can explain and build the connection between all-natural characteristics that are explained by other matters. On the contrary, this matter is also supported as the complex matter from the students' perspective and caused them to have trouble mastery this matter (Koleżyński, 2016).

Chemistry is also known as the branches of natural science that explain particles characteristic from physical and chemical properties (Chang, R., \& Goldsby, 2014). This explanation commonly made the students are difficult to master it. The concepts contained are related to an abstract and unobserved phenomenon by human senses. The fundamental concepts like the atomic structure, the periodic table system, the chemical bonding, the stoichiometry, the hydrocarbon, and the reduction-oxidation term are the series of topics that need deeper understanding by the students.

The students are required to have good representational skills when studied fundamental concepts like chemical bonding. The characteristic of this concept has the representation level 
trends on the sub-microscopic and the symbolic levels. The representation at this level can represent the real phenomenon and turn it into the signs, the symbols, and the graphics that are caused by the limitation of the human senses to observe clearly in the atoms, molecules, or the compounds (Becker et al., 2015; M. Al-Balushi, 2012; Trivic \& Milanovic, 2018). The chemical bonding sub-matter such as molecular geometry is contained many types of molecular shapes that need visualization in the learning process. The less visualization in the learning process makes the partial students cannot understand clearly when they just imagine it. It correlates with the findings that found the problem of the visualization process is related to the molecular geometry visualization (Uyulgan et al., 2014). The majority of the students cannot understand comprehensively because they cannot visualize the simple molecular geometries (Hardhy \& Syahri, 2014).

Molecular geometry is included in the harder sub-matter that the students understand it. The proof comes from the students' percentage of the right answer at the high school national examination in 2018 shows that $51,50 \%$ of the students have the right answers, this result is under the criterion that categorizes minimal completeness around 55\%. At the East Java province, particularly in Sidoarjo district, the recapitulation of high school national examination in 2018 especially on molecular geometry topics (Basic competence 3.6 "applying valence shell electron pair repulsion theory and electron domain to predict molecular geometry" (2013 Curriculum with the revision in 2016) shows that 59,65\% of the students' right answer percentage, it means that the result is far from the minimal completeness criteria. It is also supported by pre-research the students' questionnaire that shows $66 \%$ of the students from all students in the class are uninterested with the learning process, besides that, the pre-test shows that $44 \%$ of the students in the class can answer the question correctly.

Based on the chemistry teacher interview result, during the learning process in the class, the method that used only using presentation method, the using of physical learning media like molymod (molecular shapes model) is limited, and digital learning media is limited until the user of Power Point presentation that consists of the matter description that cannot represent the sub-microscopic and symbolic phenomenon, the presentation that unclearly also makes the students feel uninterested. It affects fewer students' motivation when learning chemistry. It correlates with the findings of the article research results that show the molecular geometry needs particle representation that unobserved by the students (submicroscopic level), that the students feel difficult to master it (Becker et al., 2015).

The teacher's characteristics in Industrial Revolution 4.0 era should have a teaching method to place the students as active learners and place themselves as one of the learning resources. Besides, the teacher's creativity when choosing and using the relevant learning media as well as motivating them when learning chemistry subject. The student's characteristics that include in the $21^{\text {st }}$ century generation have high sensitivity in informational technology development. It means they have the capability assets to utilize informational technologies. Their potencies are the one of huge chances by the teachers to use informational technologies in their learning process.

Interactive multimedia is one of the various learning media based on the informational technologies non-physically that have greater reliabilities (Daryanto, 2013). Besides the important roles as the facilitator between the educators and the students, it also can increase their motivation and meaningful experiences that are caused by the great view and interest of the multimedia's utilization (Asyhar, 2012). The representational skills in chemistry subject surprisingly have a great connection with the visuospatial intelligence role (Carlisle, 2015). The multimedia as a learning media that present 3-dimensional molecular geometries can help them to represent on sub-microscopic and symbolic levels and can multiply the students' visuospatial abilities (Wu \& Shah, 2014). 
. The short-term will ease the students to represent either the other materials that have the same characteristic levels or the more complex materials, while the long-term will make easier the students to make planning, projecting, and managing stuffs in their life. So, the interactive multimedia can be defined as computer software that is packed interactively and featured by various of learning substances either audio, visual or audio-visual types that help them to visualize learning matter and concept clearly.

Based on the introduction statements before, it is needed to develop the learning resources like the 3-dimensional interactive multimedia in molecular geometries form to increase the students' visuospatial abilities and help them to represent molecular geometries comprehensively.

\section{Materials and Methods}

This research is using the 4D research and development method of Thiagarajan (Ibrahim, 2001). This method is consisting of 4 main phases that begin from the Define phase that consists of five specific steps such as the curriculum analysis, the students' analysis, the tasks analysis, the concepts analysis, and the learning objective formulation. The next main step is the Design phase that consists of the criteria test framing, the media and format types choosing, and the first media design creating. The next one is the Develop phase that consists of the experts' appraisal and developmental testing. The last one is the Disseminate phase that consists of the validation testing, the packaging, and the distributing steps. This research only beholds until the Develop phase on the development testing.

The Define phase is the first main phase in this research and development method. This phase has the function to understand and decide the learning process requirements. 4 analysis steps behold in this phase from the curriculum analysis, the students' analysis, the tasks analysis, and the analysis of the concept. The result of this analysis will affect the learning objectives formulation that suits the requirements. The curriculum analysis is used to know the main learning requirement in the region. These requirements will be known from the education curriculum that is used in the schools. The students' analysis has a function to understand the students' characteristics as the research objects of this research. The understanding of an education curriculum suitable for the students' characteristics will help the researcher to formulate the learning objectives. The task analysis is a more specific step for curriculum analysis. This analysis is used to decide the students' specific tasks that need to be mastery of the learning process to achieve the expected outcomes. The concept analysis is used to understand the concept's characteristics and the learning method to be mastery of it. The result of 4 analysis is used as the reference of the learning objectives that is the student's requirements reflection on the learning process.

The Design phase is the second main phase of this research. This phase behold based on the result of the learning objectives formulation. This phase is consisting of 4 steps that begin from the criteria test framing, the media and format types choosing, and the first media design creating. The criteria test framing is the process that builds the initial component in this research. The initial component can consist of the learning resources and the validation instrument used. The framing of these components is based on the learning objectives formulation result before. The next step is the media choosing that has a function to decide the relevant media types with the concept characteristic that is analysed before. The format choosing is the specific steps after the last ones. The multimedia format that are chosen will be packed as a suit as the learning objectives. The learning objectives should be related to the students' output which is desired after using it. The first media design is the last step in this main phase. This design process is occurred based on the adjustment result from the steps before to produce the relevant learning media that is used. 
The last phase in this research is the Develop phase. This phase is the limited implementation phase to develop the relevant multimedia. This phase is consisting of two main steps (the experts' appraisal and developmental testing). The expert appraisal is the multimedia validation process on the various perspective before developmental testing. The expert appraisal process is consisting of the study process and the validation process. The study process can be occurred to collect suggestions and reviews from experts. Besides, the validation process has a function to know the expert assessment on the multimedia that is implemented on developmental testing. The developmental testing is the last step that occurred to know the multimedia utilization by the students as the learner in the molecular geometries learning. This step also takes the students assessment before and after using the multimedia to understand the effectivity of the multimedia as the media on the learning process. The one group pre-test post-test design is used as the testing and the assessment process models. The pre-test and post-test data results will be tested with a normalization test to know the normal distribution of data results. The normalized data result will be the signification value $(\alpha>0,05)$.

The data analysis process in used this research is the quantitative descriptive analysis model. The data result will process with the normalized gain score. The formula can be shown:

$$
\begin{aligned}
& \langle g\rangle=\frac{\%<G>}{\%<G>_{\max }} \\
& \langle g\rangle=\frac{\%<S_{f}>-\%<S_{i}>}{100-\%<S_{i}>}
\end{aligned}
$$

Information:

$\langle\mathrm{g}\rangle$ : Normalized Gain Score

$\left\langle\mathrm{S}_{\mathrm{f}}\right\rangle$ : Post-test Result Score

$\left\langle\mathrm{S}_{\mathrm{i}}\right\rangle$ : Pre-test Result Score

The normalized gain score is the criterion test used to compare the effect of using multimedia on the learning process and the use of conventional media on the learning process. This score can be gained by comparing the post-test and the pre-test result to obtain the score with a range of $0,0000-1,0000$ (Hake, 1999). The processing of the N-Gain result will be interpreted in the categories shown in Table 1. This interpretation is used as the benchmarks of the effectiveness of multimedia that the students used.

Table 1. N-Gain Score Interpretation

\begin{tabular}{cc}
\hline N-Gain Score $(\mathrm{g})$ & The Categories \\
\hline $\mathrm{g} \geq 0,7$ & High \\
$0,7>\mathrm{g} \geq 0,3$ & Moderate \\
$\mathrm{g}<0,3$ & Less \\
\hline
\end{tabular}

$\mathrm{N}$-Gain score in Table 1 is classified into three different categories. Each of the categories can interpret the effectivity of 3D interactive multimedia utilization as the media used in molecular geometries learning. The higher of N-Gain score obtained by the students, the higher effectivity of 3D interactive multimedia as the media that can be used on the molecular geometries learning.

The 3D interactive multimedia can be stated as the effective media if the students have the improved learning outcomes by using the multimedia with the $\mathrm{N}$-Gain score $\geq 0,7$ or with the high category or $\geq 0,3$ with the moderate category. 


\section{Results and Discussion}

The 3D interactive multimedia is the computer software that is developed with $\cdot$ html5 format and can be operated on all kinds of computer browsers. This multimedia is a portable package that shows interactive molecular geometries concepts, like the 3-dimensional molecular geometries that can rotate and move until $360^{\circ}$, 2-dimensional molecular geometries, and the exercise that all of it can help the students' visuospatial abilities. The multimedia is featured with 7 sub-menus, from the landing page, the home screen, the introduction, the phenomenon, the VSEPR theory, the hybridization theory, the real molecular geometries in nature, and the exercise.

The effectivity of 3D interactive multimedia on this research is desired by the molecular geometries pre-test and post-test results that contain the visuospatial intelligence aspect. The utilization of the instruments on this research to measure the effectiveness is the pre-test and post-test sheets about molecular geometries concepts that suitable for the visuospatial intelligence indicators. Besides, the instruments in this research are also featured with the rubric assessments. The visuospatial intelligence indicator that is used in pre-test and post-test sheets is consisted by the 3 kinds, such as molecular symmetries, molecular visualizations, and the molecular translations (Carlisle et al., 2015).

Before processing pre-test and post-test data result with the $\mathrm{N}$-Gain score, the data result should be tested to know the data's normal distribution. The normal distribution is the requirement of the utilization of the N-Gain score (Sundayana, 2014). The data result in this research will be proceed with the Kolmogorov-Smirnov normalization test with SPSS version 22.0 software. The Kolmogorov-Smirnov normalization test states that data has a normal distribution if the significance level $(\alpha) \geq 0,05$. The Kolmogorov-Smirnov normalization test in these criteria can be shown in the Table 2.

Table 2. The Kolmogrov-Smirnov Normalization Result

\begin{tabular}{cccc}
\hline \multirow{2}{*}{$\mathrm{N}$} & & VisSpas_Pretest & VisSpas_Posttest \\
\cline { 3 - 4 } & & 29 & 29 \\
\hline Normal Parameters,b & Mean & 24.4828 & 84.8276 \\
& Std. Deviation & 12.12618 & 13.78941 \\
Most Extreme Differences & Absolute & 0.227 & 0.191 \\
& Positive & 0.152 & 0.154 \\
& Negative & -0.227 & -0.191 \\
Test Statistic & & 0.227 & 0.191 \\
Asymp. Sig. (2-tailed) & & $0.053 \mathrm{c}$ & $0.085 \mathrm{c}$ \\
\hline
\end{tabular}

a. Test distribution is Normal.

b. Calculated from data.

c. Lilliefors Significance Correction.

Based on the Kolmogrov-Smirnov test result, the significance levels of two criteria (visuospatial intelligence pre-test and post-test) (Asymp. Sig. (2-tailed)) have the significance levels $(\alpha) \geq 0,05$, so it can be known that pre-test and post-test data result have the normal distribution.

\section{Discussions}

Based on the results, the pre-test and the post-test data results have the normal distribution after testing with the Kolmogrov-Smirnov test. The next process is to analyze the result of descriptive quantitatively. N-Gain score test is occurred to know the effect of interactive multimedia utilization on the learning process. The data result will be analyzed by the formula of the N-Gain score (Hake, 1999). 
Based on the N-Gain score results, it is known that the visuospatial intelligence pre-test and post-test have the $\mathrm{N}$-Gain score with the range categories from the moderate-high. It means that the 3D interactive multimedia utilization on the molecular geometries learning gives the effect on their visuospatial intelligence. Furthermore, the use of visualization media is the right path to comprehend the molecular geometries concepts. Moreover, the utilization of it can make meaningful experiences is easily absorbed by the students on the molecular geometries learning (Tuvi-Arad \& Blonder, 2010; Antonoglou, 2011).

These achievements are complemented with the question analysis on each visuospatial indicator to know the sub-matter and the students' characteristics of the concepts and molecular geometries representation. The impact of using the proper learning media will give the student an alternative path on the effort to frame independent concepts and to reinforce their representational skills (Baloyi, 2017). Also, the multimedia utilization on the learning process interactively can make the latension effect, where the probability to gain the concept stronger, is accompanied by the increasing of the visuospatial intelligence (Fernandes \& Yamanaka, 2019). The right answer percentage on the pre-test and post-test can be shown in Figure 1.

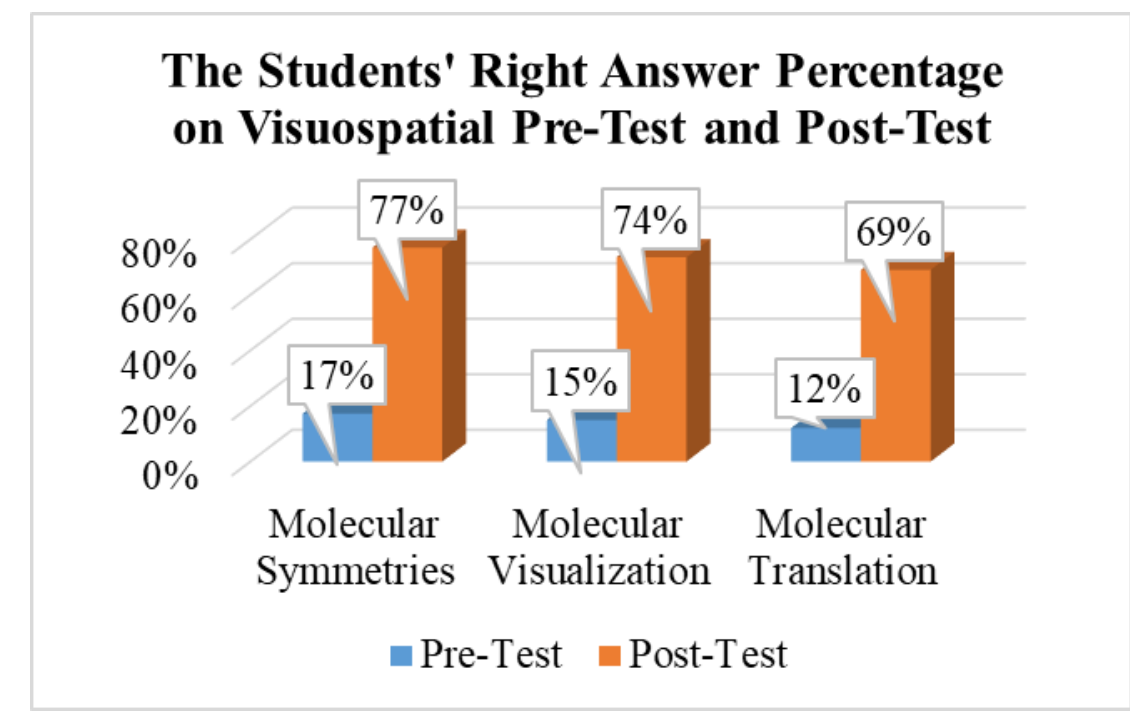

Figure 1. The Students' Right Answer Percentage on The Visuospatial Pre-Test \& Post-Test

Based on the percentage result, the molecular symetries indicator has a lower pre-test percentage caused by the irrelevant media that use in the learning process. This indicator is the visuospatial indicator that is reviewed by the simple visuospatial intelligence level. It also covers the space and the dimension aspect of the molecular geometries. It is also caused some students with lower visuospatial intelligence will understand the concepts lately. It is supported by (Uyulgan et al, 2014) findings, that Some students felt confused in understanding the molecular geometries symmetrically or asymmetrically. It makes them feel harder to understand it.

The 3D interactive multimedia that is featured with 3-dimensional molecular geometries models can reduce the confused students when they define the concepts. The models in the multimedia can be shown in the Figure 2. 


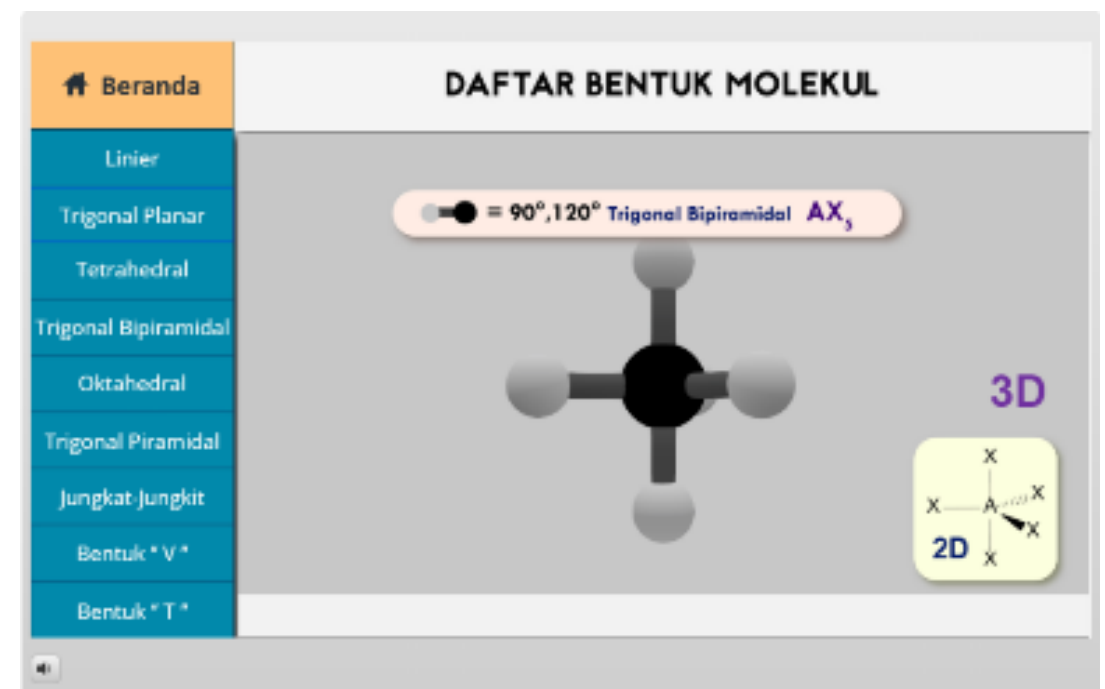

Figure 2. The Preview of 3D Molecular Geometries Models that can Rotate until $360^{\circ}$

There are nine 3D molecular geometries model shown in the multimedia. The students can operate the molecular geometries and make the rotation until $360^{\circ}$ to understand the space and dimensional aspect on the molecule and compare it with the 2D molecular geometries besides it, so it will help them to represent the symmetrical planes on each molecular type.

It is suitable for the post-test result that shows the increase of the students' right answer until 76\%. This result is related to (Wu \& Shah, 2014) that the visual shapes utilization on the molecular geometries learning can increase the students' visuospatial thinking and give a direct impact on improving their representational thinking. Moreover, the high visuospatial intelligence will affect on the students' capability to understand the symmetrical planes and give the new path to understand the molecular structure (Achuthan, et al., 2018; Tuvi-Arad \& Blonder, 2010). Besides, the symetrical planes' understanding will ease the understanding of the next related chemistry topics, such as the chirality and the polarity of the molecules (Tuvi-Arad \& Blonder, 2010).

The molecular geometries visualization is the indicator that has a higher level than the symmetrical plane indicator (Carlisle et al., 2015). The students are hoped in this indicator to visualize the molecular geometries from the chemical formula and names. It causes some students that have difficulties when understanding the formula and the chemical names will distress to make a visualization process. Based on the pre-test result in Figure 1, the students' right answer in this indicator is still around $<30 \%$. It is also relatable with the (Barrett et al., 2015) findings that found that the students commonly have difficulties in visualizing molecular geometries from the chemical formula. It causes them only to visualize it based on their assumption. Moreover, based on the findings from the many journals, the visualization mistakes in molecular geometries will lead to the same mistakes on the other visualization chemistry topics (Adytia \& Dwiningsih, 2018).

The display of interactive molecular geometries models in the multimedia is presented beside the chemical formulas and names. It occurred as an effort to help the students to visualize molecular geometries. The molecular geometries in the multimedia can be shown in the Figure 3. 


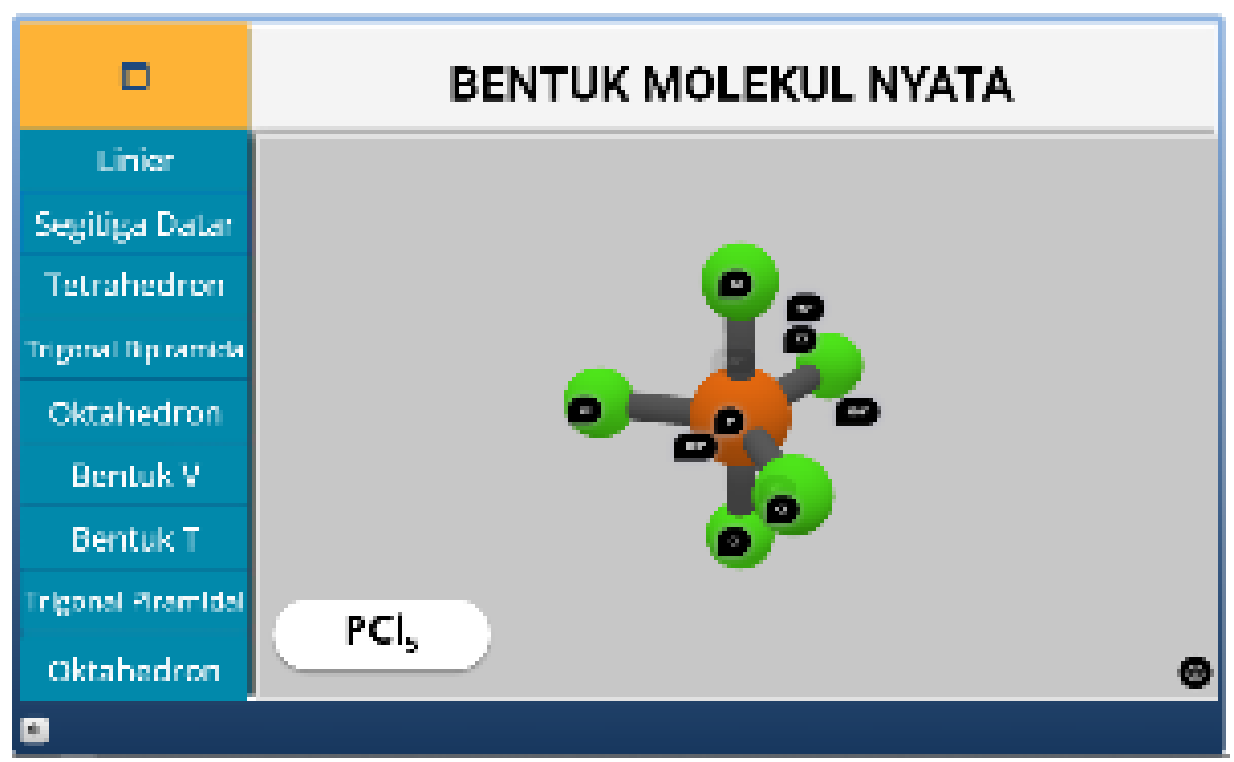

Figure 3. The Display of Molecular Geometries in 3D Interactive Multimedia.

The molecular geometries model presentation is featured with additional information like the codes, the alphabet, the atomic color, the bond angle. It has the function to help the students in visualizing the molecular geometries from the chemical formula or the chemical names. Besides, the matching process between the formulas and the molecular geometries will enrich the students' perspective to decide the molecular geometries.

Based on the visuospatial post-test, the students' right answer percentage shows the increase to $70 \%$. It related to Chang and Linn (2013) that found the media utilization illustrates the space dimension for the students will ease the students to record the geometries, so the geometries not only memorized in the short term memory (STM) but also in the long term memory (LTO). Moreover, the molecular visualization interactively will develop their comprehensive understanding from the phenomenon molecularly, and increase their visuospatial abilities (Ryoo et al., 2018).

The translation indicator is the more complex than the indicators before by involving some representational skills either on 2-dimension or 3-dimension. According to the Carlisle (2015), this indicator has a role for the students to transform the shapes in 2-dimensional (flat planes) and 3-dimensional (spaceplanes) scales. It also makes the students feel difficult that has lower representational skills. It is proved with the students' right answer percentage on the pre-test in Figure 1, the percentage result in this indicator is fairly low. The understanding of the geometries, the volume, and the angles 3-dimensionally is often to be the struggle when understanding and representing this sub-matter. The media utilization on the 2dimensional scale also inhibit their representational skills in the learning process,

The use of molecular models either on 2 dimensions or 3 dimensions in the multimedia shows on the one part as the effort to decrease the misconception gap between their representation. The model can be presented in the Figure 4. 


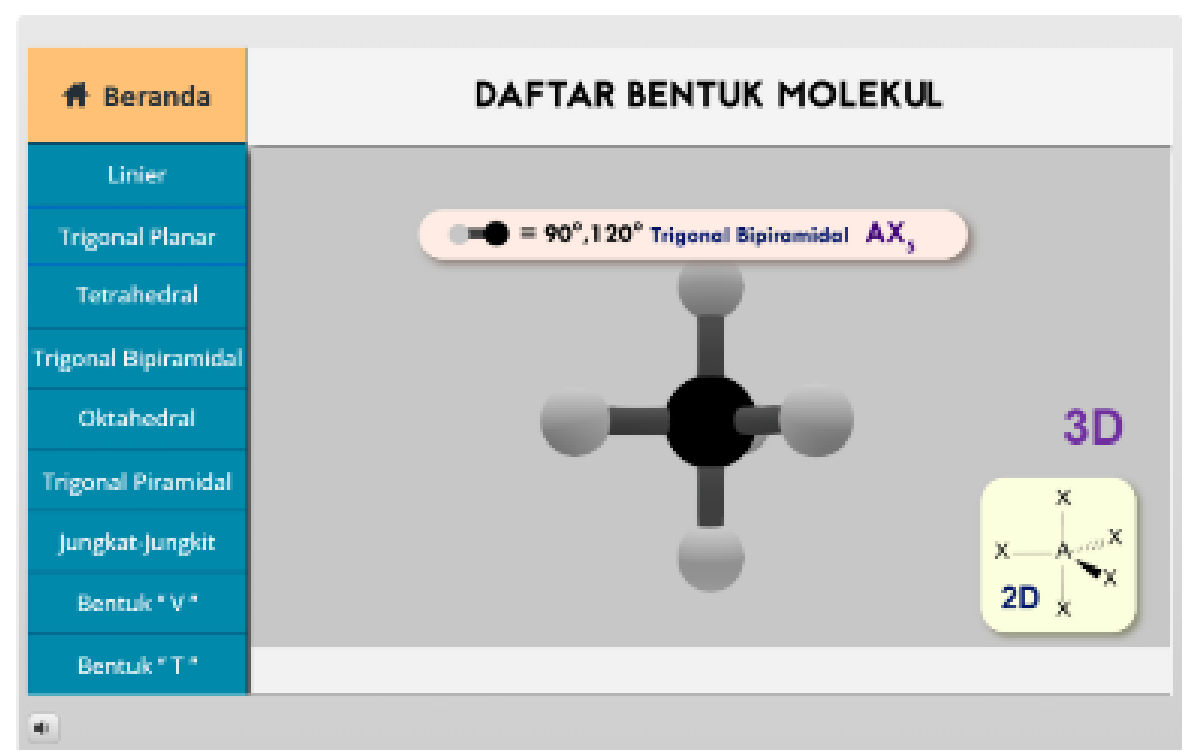

Figure 4. The Display of 2D and 3D in The Multimedia.

The molecular geometries in 2D and 3D together will help the students who have lower visuospatial abilities. It occurred because the visuospatial roles that comparison between flat and space planes will increase the student' representational skills from the simple into the complex.

It is proved by the students' right answer percentage on the post-test in this indicator, there is an increasing percentage until 65\%. It also is supported by the findings of Fatemah et al. (2020) that show the virtual models utilization in 2D and 3D will decrease the significant gap between the various students' visuospatial abilities. It also cleared with the findings of Merchant et al. (2013) that the students with lower visuospatial abilities when using 3D media will have more increasing than the students that use the $2 \mathrm{D}$ media as the learning media. Moreover, the visualization either in 2D or in 3D will give the increasing the students' capability to translate molecular geometries in other chemistry topics (Olimpo et al., 2015).

The research result shows that 3D interactive multimedia can affect significantly on the students' visuospatial intelligence. The use of a model combination between $2 \mathrm{D}$ and $3 \mathrm{D}$ has a contribution to improve their visuospatial intelligence. It is proved by the increase of the right answer from post-test and pre-test in all indicators. Furthermore, the utilization of visual models proves that helping the students when representing molecular geometries. The utilization of it should be applied to the learning process that explains the visualization aspect, so the students understanding does not only depend on their assumption and imagination, but also the increasing visuospatial and representational skills that are caused by the relevant learning media utilization.

\section{Conclusion}

Based on the research and the development result using 4D R\&D Thiagarajan was modified by the Ibrahim method, 3D interactive multimedia on the molecular geometries sub-matter can be stated as effective as the media that can increase the students' visuospatial intelligence. The effectivity of this multimedia can be reviewed from the developmental testing result that uses the one group pre-test post-test model shows the increasing of the students' right answer percentage $>50 \%$ and the $\mathrm{N}$-Gain score interpretation with the range between $0,5174-1,0000$ on the moderate and the high categories. It means the different result occurrs when using multimedia as the media on the learning process than using conventional media. 


\section{References}

Achuthan, K., Kolil, V. K., \& Diwakar, S. (2018). Using Virtual Laboratories in Chemistry Classrooms As Interactive Tools Towards Modifying Alternate Conceptions in Molecular Symmetry. Education and Information Technologies, 23(6), 2499-2515. https://doi.org/10.1007/s10639-018-9727-1

Adytia, P. F., \& Dwiningsih, K. (2018). Pengembangan Lembar Kegiatan Siswa Berorientasi Literasi Sains Pada Materi Ikatan Kimia. UNESA Journal of Chemical Education, 7(3), $358-364$.

Antonoglou, L. D., Charistos, N. D., \& Sigalas, M. P. (2011). Design, Development and Implementation of a Technology Enhanced Hybrid Course on Molecular Symmetry: Students' Outcomes and Attitudes. Chemistry Education Research and Practice, 12(4), 454-468. https://doi.org/10.1039/C0RP90013C

Asyhar, R. (2012). Kreatif Mengembangkan Media Pembelajaran. Jakarta.

Baloyi, L. L., Ojo, S. O., \& Van Wyk, E. A. (2017). Design and Development Of An Interactive Multimedia Simulation For Augmenting The Theacing and Learning Of Programming Concepts. ERIC, 67-93.

Barrett, T. J., Stull, A. T., Hsu, T. M., \& Hegarty, M. (2015). Constrained Interactivity for Relating Multiple Representations in Science: When Virtual Is Better Than Real. Computers and Education, 81, 69-81. https://doi.org/10.1016/j.compedu.2014.09.009

Becker, N., Stanford, C., Towns, M., \& Cole, R. (2015). Translating Across Macroscopic, Submicroscopic, and Symbolic Levels: The Role of Instructor Facilitation In An Inquiry-Oriented Physical Chemistry Class. Chemistry Education Research and Practice, 16(4), 769-785. https://doi.org/10.1039/c5rp00064e

Carlisle, D., Tyson, J., \& Nieswandt, M. (2015). Fostering Spatial Skill Acquisition by General Chemistry Students. Chemistry Education Research and Practice, 16(3), 478517. https://doi.org/10.1039/c4rp00228h

Chang, R., \& Goldsby, K. A. (2014). General Chemistry: The Essential Concepts (Seventh Ed). New York: McGraw-Hill.

Chang, H. Y., \& Linn, M. C. (2013). Scaffolding Learning from Molecular Visualizations. Journal of Research in Science Teaching, 50(7), 858-886. https://doi.org/10.1002/tea.21089

Daryanto. (2013). Media Pembelajaran. Yogyakarta: Gava Media.

Fatemah, A., Rasool, S., \& Habib, U. (2020). Interactive 3D Visualization of Chemical Structure Diagrams Embedded in Text to Aid Spatial Learning Process of Students. Journal of Chemical Education, 97(4), 992-1000. https://doi.org/10.1021/acs.jchemed.9b00690

Fernandes, R., \& Yamanaka, T. (2019). Interactive Design vs. Design for Interaction: Developing Interactive Play Tools that Promote Interactions between Children. In Interactive Multimedia - Multimedia Production and Digital Storytelling. IntechOpen. https://doi.org/10.5772/intechopen.84328

Ghibaudi, E., Cerruti, L., \& Villani, G. (2019). Structure, Shape, Topology: Entangled Concepts in Molecular Chemistry. Foundations of Chemistry, 1-29. 
https://doi.org/10.1007/s10698-019-09333-8

Hake, R. R. (1999). Analyzing Change/Gain Scores. American Educational Research Association, (Division D), 1-4.

Hardhy, J., \& Syahri, W. (2014). Pengembangan Media Pembelajaran dengan Lectora Inspire Materi Bentuk Molekul untuk Siswa Kelas X IPA SMAN 10. J. Ind. Soc. Integ. Chem., 2015, 7(2), 18-28.

Ibrahim, M. (2001). Model Pengembangan Perangkat Pembelajaran Menurut Jerold E. Kemp \& Thiagarajan. Surabaya: PSMS-PPS UNESA.

Koleżyński, A. (2016). The Concepts of An Atom and Chemical Bond in Physics and Chemistry: The Role of Approximations. Semina Scientiarum, 10(0), 31. https://doi.org/10.15633/ss.1555

M. Al-Balushi, S. (2012). The Effect of Macroscopic and Submicroscopic Pictorial Representations on Pre-Service Science Teachers' Explanations. International Journal of Academic Research, 4(6), 10-14. https://doi.org/10.7813/2075-4124.2012/4-6/b.2

Merchant, Z., Goetz, E. T., Keeney-Kennicutt, W., Cifuentes, L., Kwok, O., \& Davis, T. J. (2013). Exploring 3-D Virtual Reality Technology for Spatial Ability and chemistry Achievement. Journal of Computer Assisted Learning, 29(6), 579-590. https://doi.org/10.1111/jcal.12018

Olimpo, J. T., Kumi, B. C., Wroblewski, R., \& Dixon, B. L. (2015). Examining The Relationship Between 2D Diagrammatic Conventions and Students' Success on Representational Translation Tasks in Organic Chemistry. Chemistry Education Research and Practice, 16(1), 143-153. https://doi.org/10.1039/c4rp00169a

Ryoo, K., Bedell, K., \& Swearingen, A. (2018). Promoting Linguistically Diverse Students' Short-Term and Long-Term Understanding of Chemical Phenomena Using Visualizations. Journal of Science Education and Technology, 27(6), 508-522. https://doi.org/10.1007/s10956-018-9739-z

Sundayana, R. (2014). Statistika penelitian pendidikan. Bandung: Alfa Beta.

Trivic, D. D., \& Milanovic, V. D. (2018). The Macroscopic, Submicroscopic and Symbolic Level in Explanations of A Chemical Reaction Provided by Thirteen-Year Olds. Journal of the Serbian Chemical Society, 83(10), 1177-1192. https://doi.org/10.2298/JSC171220055T

Tuvi-Arad, I., \& Blonder, R. (2010). Continuous Symmetry and Chemistry Teachers: Learning Advanced Chemistry Content Through Novel Visualization Tools. Chemistry Education Research and Practice, 11(1), 48-58. https://doi.org/10.1039/c001046b

Uyulgan, M. A., Akkuzu, N., \& Alpat, Ş. (2014). Assessing The Students' Understanding Related To Molecular Geometry Using A Two-Tier Diagnostic Test. Journal of Baltic Science Education, 13(6), 839-855.

Wu, H.-K., \& Shah, P. (2014). Exploring Visuospatial Thinking in Chemistry Learning. Science Education, 88(3), 465-492. https://doi.org/10.1002/sce.10126 